\title{
Building Biotechnology: Starting, Managing, and Understanding Biotechnology Companies*
}

\author{
Sergio Marshall \\ Director Programa Doctorado en Biotecnología \\ Instituto de Biología \\ Pontificia Universidad Católica de Valparaíso \\ Chile \\ E-mail:smarshal@ucv.cl
}

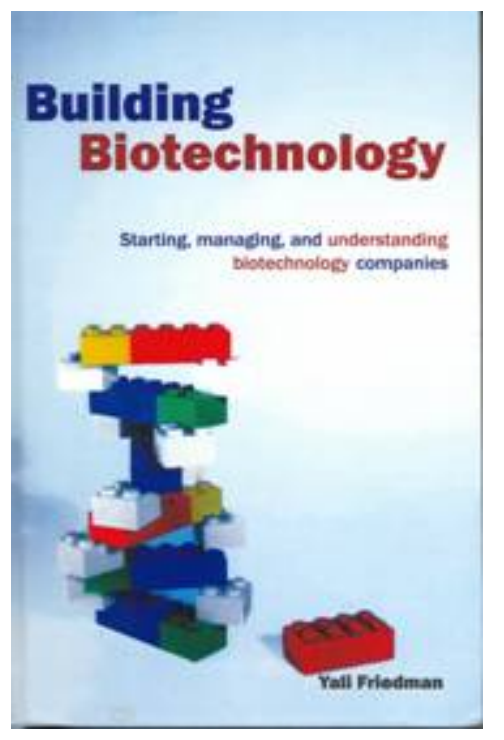

Since Biotechnology and a large number of comprehensive textbooks have reached the market. Nonetheless only a few of them are primarily devoted to outstand related key disciplines that makes

Biotechnology a commercially appealing science. This is the case for "Building Biotechnology" by Yali Friedman. From the title on, in well-structured four main sections, the reader is smoothly driven in a dynamic and convincing way to understand the interactions of the scientific aspects of biotechnology with legal, political, regulatory and even ethical approaches required to make biotechnology a commercial success. Indeed, the opening chapters introduce readers to the real concept of applied biotechnology, defined not only as a product or service making one, but as a mixture of technologies that altogether and in harmony allow the development of a long-lasting commercial biotechnology. Particularly noticeable is the clarifying chapter on legal issues and the differentiation between the intertwined concepts normally associated with the issue of intellectual property. Next, the author dives the reader into corporate biotechnology, highlighting the requirements to establish a biotechnology company. This is a pivotal issue for pure-science biotechnologists, regularly deprived of the required background to build-up from bench to market. The last section is a well organized basic tour through relevant issues that get together science and technology as a functional unit. It clearly shows the reader that being successful in biotechnology is not $\mathrm{t}$ an easy task, but not impossible either if the proper steps are followed. Notwithstanding, one of the key concept resulting from reading the book is that of optimism. Biotechnology has destroyed paradigms, created new ones and reborn others, always with a positive slope, selling the feeling that we are just at the beginning of a never-ending process.

Yali Friedman is an enthusiast. Through the different sections of his book he speeds up to convince the reader that getting into Biotechnology is a must. In summary, a robust, commercially-oriented readable book which should be read not only by specialists but also by entrepreneurs which foresee Biotechnology as the business of tomorrow.

*Title: Building Biotechnology: Starting, Managing, and Understanding Biotechnology Companies Author: Yali Friedman Details: 2004, 264 pp. ISBN: 0-9734676-2-2 